\title{
Application of Flexsim in Cultivating Logistics Management Professionals
}

\author{
Yuan Shao, Xin Suo, Ya-juan Wang ${ }^{*}$ \\ College of Management \\ Wuhan University of Science and Technology \\ Wuhan, China \\ shaoyuan@wust.edu.cn,wangyajuan@wust.edu.cn
}

\begin{abstract}
In this paper, we first present the characteristics and problems existing in the process of logistics management teaching, and then analyze the advantage of the application of system modeling and simulation in logistics management teaching. An example is proposed to illustrate how to apply the software Flexsim to construct the simulation model and analyze a logistics system, to uncover the existing problem, and to optimize this logistics system.
\end{abstract}

Keywords—Flexsim; simulation; logistics management teaching; talent cultivation

\section{INTRODUCTION}

The center of the global logistics market is transferring from America and Europe to Asian countries like China and Ind ia. For example, in recently years, the average annual increasing rate of the third-party logistics market is about $8.9 \%$ in Asia, $14.4 \%$ in China, and $12.3 \%$ in India. It is expected that China and India will continue to lead in the increasing speed of the third-party logistics market. According to the investment analysis and perspective forecasting report on China's logistics industry in the years of 2016-2020, the logistics market of China is experiencing a great development opportunity [1].

In the context of economic globalization, the emerging modes of global sourcing and manufacturing makes logistics activities more active among different countries and regions, this gives unprecedented challenging for professional logistics companies. Under such Under background, logistics industry has become a promising industry and hence logistics-related majors also become vey popular in universities. However, in practice, on one hand, logistics companies pay highly attentions to logistics profes sional skills and are more prone to employ the employees who have work experience for several years; on the other hand, the graduates of logistics-related majors do not have sufficient practical experience and hence may well be not able to meet the requirements of the logistics companies. Such mismatching between supply and demand of logistics professionals puts forward a task for universities on cultivating the student in the aspect of practical ability. Correspondingly, utilizing simulation software in teaching process becomes a feasible and popular method in enhancing students' practical abilities.

It is shown by investigating data that at present the shortage of logistics professionals approaches six millions and that of the respective logistics management professionals about five hundreds of thousands [2]. Dengcai He, vice present of the China Federation of Logistics and Purchasing, deems that the development of logistics industry must depend on logistics professionals. In the context of "Internet plus" and "One Belt One Road", the future of logistics needs not only the skilled professionals and management professionals, but also compound talents who are specialized, internationalized, and internet-enabled. How to reform the cultivating mode of logistics professionals, construct internationalized educating platform, and extend the internationalized market of logistics professionals has become a major concern of and problem faced by logistics industry.

Logistics management major is a discipline with the close combination of theory and practice because the rapid development of logistics industry requires the logistics professionals to have strong technical capacity and practical abilities. This proposes a high requirement for cultivating logistics management professionals and respective teaching works. At present, there exist two main problems on logistics management teaching. First, teaching mode cannot meet the requirements of the logistics industry. Second, there exist an apparent gap between the practical operating skill of the students required by employers and their ability [3]. This paper, by departing from the authors' teaching practice, finds that adopting logistics system simulation is a feasible way to deal with these problems, and plays an important role in promoting the students to master the knowledge on the design, operations and optimization of the logistics and production systems. 


\section{THE APPLICATION ADVANTAGES OF LOGISTICS SYSTEM SIMULATION IN LOGISTICS MANAGEMENT TEACHING}

In addition to teach basic knowledge and fundamental principle and of logistics, logistics management major also needs to educate the student to have the practical operation capability and to be adapted to the objective of internationalize talents. Therefore, the university having logistics management major needs to build logistics lab and purchase respective facility and equipments. However, setting up logistics lab requires considerable financial investment and space and the carrying cost is also very high. Compared with lab building, applying logistics simulation software in the teaching process can not only simulate the whole supply chain and logistics system, save cost and adapt to the high development speed of modern logistics technology, but also solve the practical problems without disrupting or damaging the running system [4]. Being closely related to practical logistics environment, logistics simulation software can model the realistic logistics system and utilize computer simulation to solve realistic problem in logistics operation. Therefore, logistics simulation software can facilitate the understanding of student towards the design and operations process of the logistics system, stimulate their learning interests and promote their learning efficiency.

\section{FLEXSIM AND CULTIVATION OF LOGISTICS MANAGEMENT PROFESSIONALS}

\section{A. Introduction to Flexsim}

Flexsim is simulation software of a new generation developed by FlexSim Software Products, Inc. located in United States. It uses an OpenGL environment to realize real-time 3D rendering and it is the only simulation software that incorporates a C++ IDE and compiler in the graphic modeling environment. The simulation by using Flexsim can realize the visualization of production process, which helps companies to optimally allocate resource and to maximize capacity, optimize scheduling, minimize inventory and minimize costs. In the aspect of model component, Flexsim has a mass of simulation subjects involved in logistics such as logistics machines, operating workers, conveyors, forklifts, traffic lights, containers, automatic pilers, etc. Flexsim can also custom the components based the existing components, and then add these customized components into the model base and use them like the existing components. In the aspect of data analysis, Flexsim has queuing graph, bar graph, pie graph [5]. Meanwhile, we can conveniently observe dynamic data in the course of simulation and import and export data, and proceed data exchange, which facilitate our analysis on logistics systems optimization and comparison. Because of a number of merits, Flexsim plays an essential role in logistics management professional cultivation.

\section{B. Cultivating the ability of logistics professional based on Flexsim}

The authors deem that the cultivation of the ability of logistics professional based on Flexsim should obey the following basic idea. First, we should depart from the fundamental needs of the company and adopt order-based education. According to the requirements of logistics industry, the demand towards the logistics professionals focuses on four aspects including warehousing, transportation, distribution and information management. After specifying the directions of cultivating the ability of the logistics professional, we need to build respective simulation models based on specific business scope, for example, building the Flexsim warehousing and transportation simulation models. Then, we need to gradually perfect the simulation models according to the results of realistic data and investigation, e.g., the operation speed and time, path of the mechanical equipments. This helps students to be familiar with the logistics business and promote their abilities of processing the business. In addition, we need to an alyze the problems in logistics business process by combining the simulation data with the data on processing practical business, and then examine the improvement strategy based on the simulation models. This helps promote the management ability of the logistics management professionals.

\section{The application of Flexsim simulation in logistics: an example with distribution center}

Distribution center is one type of modern logistics facility that is used for goods distribution and delivery in order to provide sale and supply services for customers. Different from traditional warehousing facility, in modern business society, distribution center has become the center of business flow, product flow and information flow for chain enterprises. Because of this, distribution center is a key facility that ensures the normal operation of chain enterprises.

This example applies the simulation software Flexsim to construct a corresponding simulation model of distribution center. This model can three-dimensionally exhibit three different processes related to purchasing from supplier, shipping to the retailer and inventory management, respectively. It can also adjust the parameters of the equipment (for example, the arriving rate of goods and inventory threshold values of storage rack) and vividly exhibit the functions and operation principles of these equipment. In addition, by graphically showing the statistic values of the vacancy rate, average processing time and the minimal and maximal capacities of the equipment, we can easily uncover the bottleneck of the equipment and thereby can promote the system efficiency. Further, continuously refining and improving the Flexsim simulation model of the distribution center contributes to promoting the model users' ability of managing the distribution center.

The following process is a typical modeling process of the distribution center. The distribution center replenishes from three supplier and ships to three manufacturers. The corresponding logistics system is graphically shown in Figure 1 . The objective of the simulation is to investigate the inventory cost and profit of the distribution center and how to improve them. The model setting is described as follows. 
- The suppliers: each of the three suppliers starts to make the product if the inventory level of the product supplied by the supplier in the distribution center is less than 10, and stops making the product if the inventory level approaches 20 . Supplier 1 and supplier 2 supplies one unit product per 4 hours to the distribution center, and supplier 3 supplies one unit product within a time uniformly distributed between 3-6 hours.

- Shipping of the distribution center: the distribution center stops making replenishment to each of the three manufacturers if the manufacturer's inventory level is less than 10. The distribution center makes replenishment to manufacturer 1 if his inventory level is less than 2, to manufacturer 2 if his inventory level is less than 3 , and to manufacturer 3 if his inventory level is less than 4.

- Costs and revenues of the distribution center: purchasing cost=3 Yuan/unit; selling price=5 Yuan/unit; inventory carry cost is 1 Yuan per 100 hours.

- The manufacturers: the three manufacturers produce their products continuously. manufacturer 1 needs 6 hours to make one unit of product, manufacturer 2 needs a time uniformly distributed between 3-9 hours to make one unit of product, and manufacturer 3 needs a time uniformly distributed between 2-8 hours to make one unit of product.

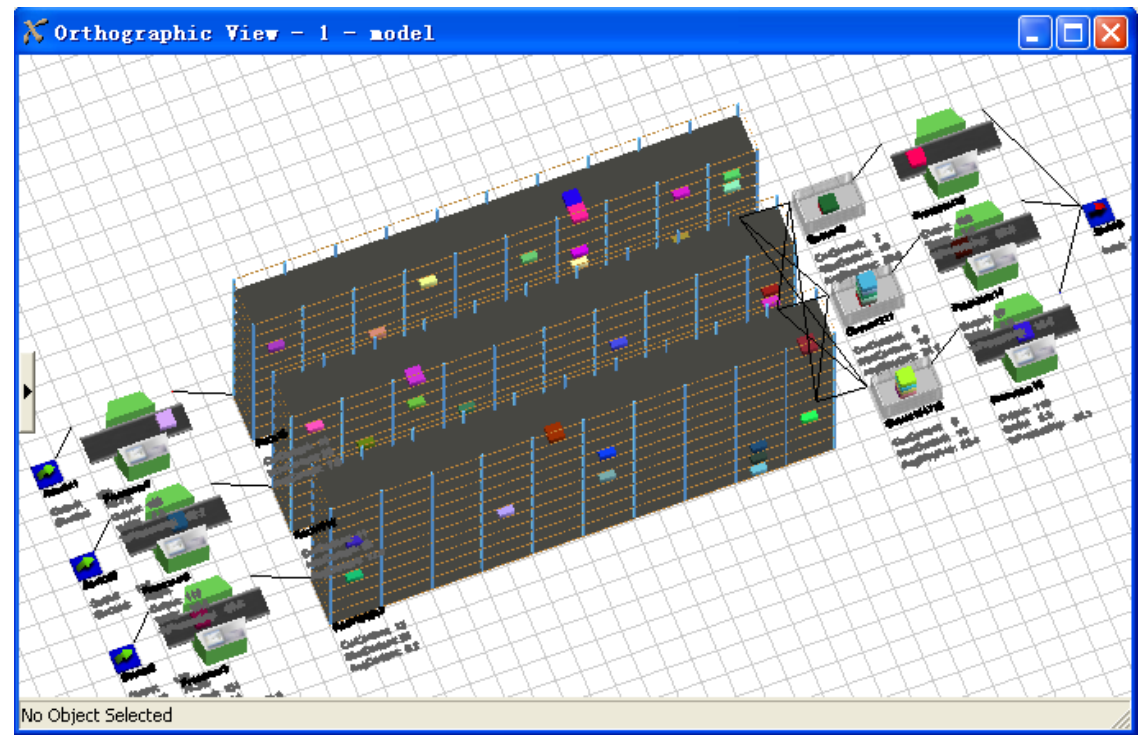

Fig. 1. Example The three-demension gragh of the logistics system with distribution center

In Figure 2, the data useful for our analysis include: 1) average inventory per hour in the rack=12.32 (corresponding to "average" under "content"); 2) total imported amount of product in the running time of the rack=1751 (corresponding to "Input" under "Throughput"); 3) total imported amount of product in the running time of the rack =1751 (corresponding to "Output" under “Throughput").

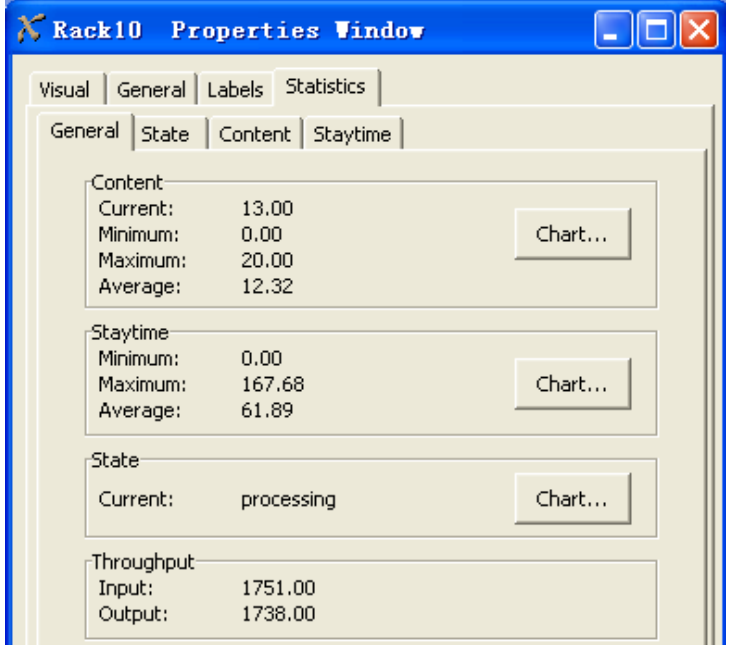

Fig. 2. Related simulation data on the rack 
Based on the above data and product cost set in the model, we can obtain the revenue on the rack in the distribution center as follows:

- Total purchasing cost: $1751 \times 3=5253$ (Yuan)

- Total revenue: $1738 \times 5=8690$ (Yuan)

- Total inventory carrying cost: $12.32 \times 8760 / 100 \times 1=1079$ (Yuan)

- Total profit: $8690-5253-1079=2358$ (Yuan)

By applying the same method, we can calculate the revenues of the other two racks, and their profits are 2323 and 2519 , respectively (considering that the data are randomly given, we do not enumerate different indices and only provide the results and method). Therefore, we can obtain that the total profit of the distribution center is 7200 Yuan (which equals the sum of 2358, 2323 and 2519).

In order to investigate the impact of inventory level on the profit of the distribution center, we can change the maximal storage capacity of each rack (the related data can be set in "OnEntry" under the term "RackTriggers" of the parameter page) and the replenishment condition (i.e., the minimal inventory level below which the replenishment occurs; the related data can be set in "OnExit" under the term "RackTriggers" of the parameter page). Based on such a change, we can operate the simulation model and conduct data analysis, and then obtain the optimal parameter setting that maximizes the profit of the distribution center through comparing different parameter settings.

\section{SUMMARY}

This paper investigates the application of the simulation software Flexsim in the cultivation process of logistics management professionals, including the problems existing in the cultivation process and the advantage of logistics system modeling and simulation applied in teaching. Finally, we use an example of a distribution center system to show how to apply Flexsim to an alyze and optimize the logistics system.

\section{ACKNOWLEDGMENT}

This research was financially supported by the National Science Foundation of China (71501147), Cultivation plan project for young scholar at Wuhan University of Science and Technology (250089) and Teaching research project at Wuhan university of science and technology (2015X037).

\section{REFERENCES}

[1] [1] X.R. Li, B.X. Gao, Z.Y. Shen and J.M. Cai, 2016-2020 Investment Analysis and Perspective Forecasting Report on China’s Logistics Industry [M]. China investment advisory Research Center for industry and policy, 2017.

[2] [2] X.F. Ran, Simulation- New Direction of Logistics Teaching [J]. Logistics engineering and management, 2010,(1):135-138.

[3] [3] Information on http://news.chinawutong.com/

[4] [4] L. Shan, J.Z. Ma, The existing problems and countermeasures in the construction of logistics teaching laboratory in modern colleges and universities [J]. logistics technology, 2012, 31(10):185-187.

[5] [5] X.G. Ma, T.J. Liu, Modeling, simulation and application of modern logistics system [M]. Beijing: Science Press, 2012 